\title{
Posttherapy Clinical TNM Finding
}

National Cancer Institute

\section{Source}

National Cancer Institute. Posttherapy Clinical TNM Finding. NCI Thesaurus. Code

C143081.

Clinical TNM staging performed following systemic therapy or radiation. 